\title{
ОБЕСПЕЧЕНИЕ БЕЗОПАСНОГО СОСТОЯНИЯ ВЗТ В РАЙОНЕ РАЗМЕЩЕНИЯ СОЛЕОТВАЛА
}

\author{
С.Ю. ЛОБАНОВ \\ Горный институт УрО РАН, г. Пермь.
}

\begin{abstract}
Аннотация: Рассматривался участок отработки калийных солей, находящийся в зоне влияния солеотвала, что обуславливает дополнительную нагрузку на междукамерные целики и, как следствие, ведет к увеличению степени их нагружения. Для обеспечения долговременной сохранности водозащитной толщи планируется создание зоны смягчения по пласту КрІІ на исследуемой площади. В этой связи, возникла необходимость оценки эффективности обеспечения долговременной сохранности водозащитной толщи за счет создания зоны смягчения по пласту КрII под резервными площадями солеотвала.

Математическое моделирование, направленное на определение безопасных условий подработки В3Т, проводилось в плоской постановке методом конечных элементов. Связь между деформациями и напряжениями на допредельной стадии описывалась законом Гука, а предельные напряжения в области сжатия определялись критерием Кулона-Мора. Для анализа нарушения сплошности пластов ВЗТ в области действия растягивающих напряжений использовался предел прочности при растяжении.

Геомеханический анализ состояния водозащитной толщи показал, что в отсутствии дополнительных мер охраны водозащитной толщи, на конец процесса сдвижения формируются области субвертикальной нарушенности. Их наличие создает опасность проникновения надсолевых вод в выработанное пространство. Исследования показали, что создание зоны смягчения ведет к значимому улучшению горнотехнической ситуации в проблемном районе и является эффективной дополнительной мерой охраны водозащитной толщи на участке, планируемом для размещения солеотходов.
\end{abstract}

Ключевые слова: математическое моделирование; геомеханическая оценка; водозащитная толща; солеотвал; меры охраны.

Площадь исследований в районе целика между западным (73П) и восточным (7ВП) крылом рудника БКПРУ-2 характеризуется относительно сложным горно-геологическим строением, аномалией, выделенной по результатам сейсморазведочных работ, а также дополнительной пригрузкой несущих элементов камерной системы разработки под действием собственного веса солеотходов, планируемых к размещению на краевых частях 7 ЗП, 9 ЗП.

В пределах рассматриваемой площади отработаны два сильвинитовых пласта: КрII и АБ. Очистные работы проводились в 1981-2012 годах.

Математическое моделирование напряженно-деформированного состояния подработанного массива проводилось по широтному профилю, проходящему по 7 ЗП - 7ВП и пересекающему маркшейдерские профиля «Рассолосборник» и «Шламохранилище». Профиль ориентирован с запада на восток.

Для обеспечения долговременной сохранности водозащитной толщи планируется создание зоны смягчения по пласту КрII в районе целика между 7 ЗП и 7 ВП панелями в 2019 году. Проектные параметры отработки на участке зоны смягчения принимались: вынимаемая мощность $m=3.2 m$, ширина камеры $a=3.2 m$, ширина целиков $b=8.3 м$. Ширина зоны смягчения составляет 135 метров.

Участок отработки находится в зоне влияния солеотвала, что обуславливает дополнительную нагрузку на междукамерные целики и, как следствие, ведет к увеличению степени их нагружения [1].

$$
C=\xi \frac{\gamma l H_{0}}{b \sigma_{n}},
$$

где $\xi$ - коэффициент, учитывающий изменение нагрузки на целики вследствии влияния горнотехнических факторов; $\gamma$-объемный вес налегающей толщи пород; $l$-межосевое расстояние; $H_{0}$ - максимальное значение расстояния от земной поверхности до кровли целиков на рассматриваемом участке отработки; $b$-расчетная ширина целиков; 
$\sigma_{n}$-расчетная прочность пород. Коэффициент, учитывающий изменения нагрузки на целики, определяется выражением:

$$
\xi=\xi_{1} \xi_{2} \xi_{x}
$$

где $\xi_{1}$-коэффициент учитывающий влияние техногенной нагрузки, связанной с дополнительной пригрузкой от солеотвала, определяется по формуле:

$$
\xi_{1}=1+\frac{m_{s} \gamma_{s} H_{s}}{2 \lambda_{s} \gamma H_{0}},
$$

где $m_{s}$-коэффициент учитывающий расположение рассматриваемого участка отработки относительно контура солеотвала; $\lambda_{s}$ - параметр характеризующий отношение ширины зоны влияния солеотвала к ширине основания солеотвала на земной поверхности; $\gamma_{s}$-объемный вес солеотвала; $H_{s}$-расчетная высота солеотвала.

Положение участка относительно контура солеотвала представлено на рис. 1.

Построение физико-геологической модели разреза в юго-западной части шахтного поля рудника БКПРУ-2 осуществлялось на основе результатов сейсморазведочных работ и данных бурения геологоразведочных скважин.

Математическое моделирование состояния В3Т выполнялось в упругопластической постановке с учетом техногенной нагрузки, связанной с пригрузкой от солеотвала и всего комплекса горно-геологических (особенности строения, гипсометрия пластов и др.) и горнотехнических (количество отработанных пластов, параметры системы разработки, порядок отработки, наличие закладки выработанного пространства и т.д.) факторов. Для анализа деформирования подработанного массива во времени использовался реологический подход, основанный на математическом описании прогнозных графиков нарастания оседаний земной поверхности [2].

Оценка степени изменения состояния водозащитной толщи при развитии процесса сдвижения базировалась на анализе потенциальной возможности формирования в массиве трещин субвертикальной ориентации. Для рассматриваемой идеальной упругопластической среды связь между деформациями и напряжениями на допредельной стадии описывалась законом Гука, а предельные напряжения в области сжатия определялись критерием Кулона-Мора [3]. В области растяжения критическое напряжение ограничивалось пределом прочности на растяжение.

Численная реализация осуществлялась методом конечных элементов в перемещениях [4] с дискретизацией рассматриваемой области на треугольные элементы первого порядка. Решение упругопластической задачи основывалось на методе начальных напряжений $[5,6]$.

Анализ изменения напряженнодеформированного состояния водозащитной толщи и оценка еe устойчивости вдоль расчетного профиля выполнялись на текущий момент времени и на последующие годы вплоть до конца процесса сдвижения земной поверхности.

Для оценки влияния зоны смягчения на сохранность ВЗТ рассмат-

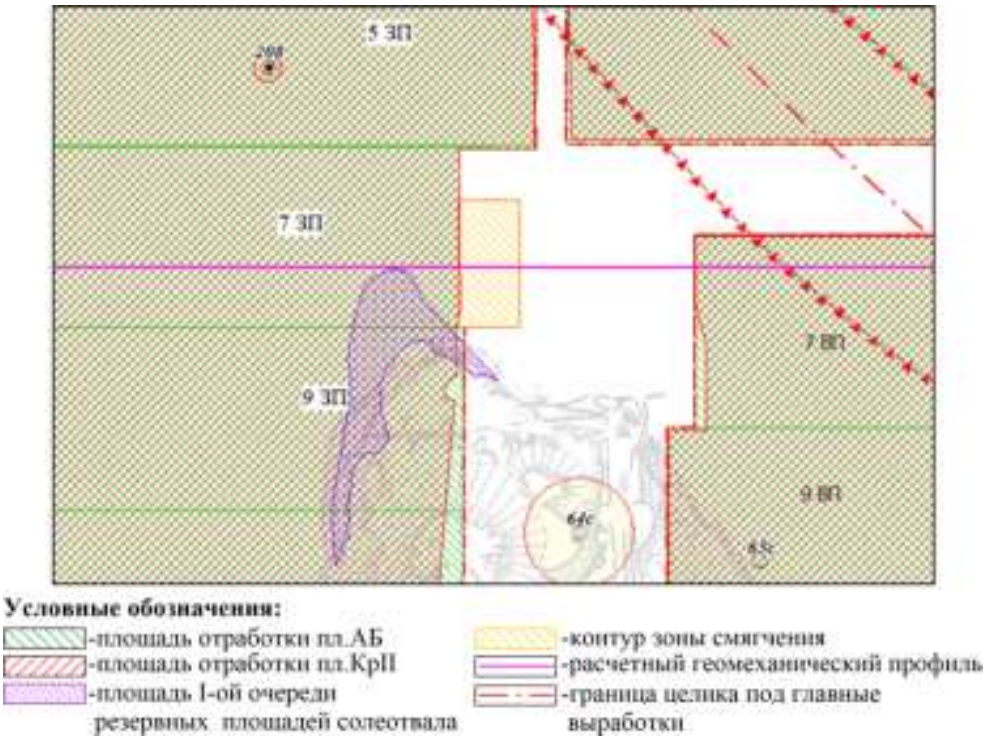

Рис. 1. Положение зоны смягчения относительно контура солеотвала 
ривались два варианта расчетов: с планируемой зоной смягчения по пласту КрІІ и без нее.

Создание у восточной границы 7 ЗП зоны смягчения протяженностью 135м за счет отработки пласта КрII ведет к значительной перемене горнотехнической ситуации в районе целика между 7 ЗП и 7 ВП. Все изменения напряженно-дефомированного состояния ВЗТ связанные с отработкой зоны смягчения, согласно геомеханическим расчетам, проявляются на конец процесса сдвижения.

На рис. 1.2 представлены оседания земной поверхности вдоль расчетного геомеханического профиля на конец процесса сдвижения. Создание зоны смягчения по пласту КрII обусловливает уменьшение градиента оседаний земной поверхности над западной границей целика между восточным и западным флангами шахтного поля (кривая №2 на рис. 2), что, априори, улучшает геомеханическую ситуацию на данном участке. Изменения в характере формирования оседаний земной поверхности в рассматриваемой области оказывают влияния на все параметры, оценивающие напряженно-деформированное состояние ВЗТ.

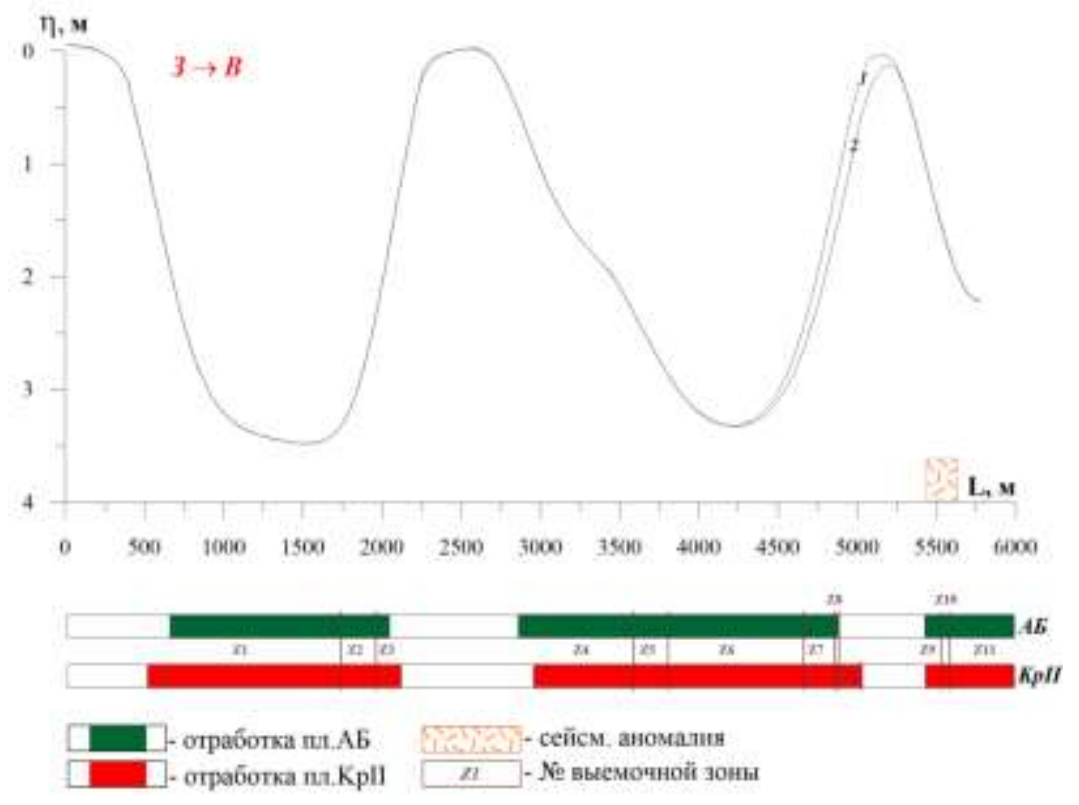

Рис. 2. Расчетные оседания земной поверхности вдоль геомеханического профиля на конец процесса сдвижения: 1- без зоны смягчения; 2- с зоной смягчения

На рис. 1.3. представлены результаты, иллюстрирующие разрушение пластов В3Т вдоль расчетного профиля на конец процесса сдвижения.

При отсутствии зоны смягчения прогнозируется формирование ярко выраженной области техногенной нарушенности пластов ВЗТ на западной границе целика между 7 ЗП и 7 ВП, где целостность сохраняют только ПКС и частично соляные пласты ПП (рис. 1.3).

Отработка зоны смягчения по пласту КрII обуславливает снижение техногенной нагрузки на ВЗТ. Это проявляется в уменьшении интенсивности разрушения слагающих ее пластов (рис. 1.4) в сравнении с вариантом отсутствия на данном участке зоны смягчения (рис. 3).

Создание у восточной границы 7 ЗП зоны смягчения протяженностью 135 м за счет отработки пласта КрII ведет к значимому улучшению горнотехнической ситуации в районе целика между 7 ЗП и 7 ВП. В этом случае на конец процесса сдвижения зона техногенной нарушенности ограничивается карналлитовыми пластами от В до 3 и пластами каменной соли Б-В, В-Г и Г-Д (рис. 4).

Таким образом, создание зоны смягчения в районе западной границы целика между флангами шахтного поля является эффективной дополнительной мерой охраны ВЗТ на участке, планируемом для размещения солеотходов. 


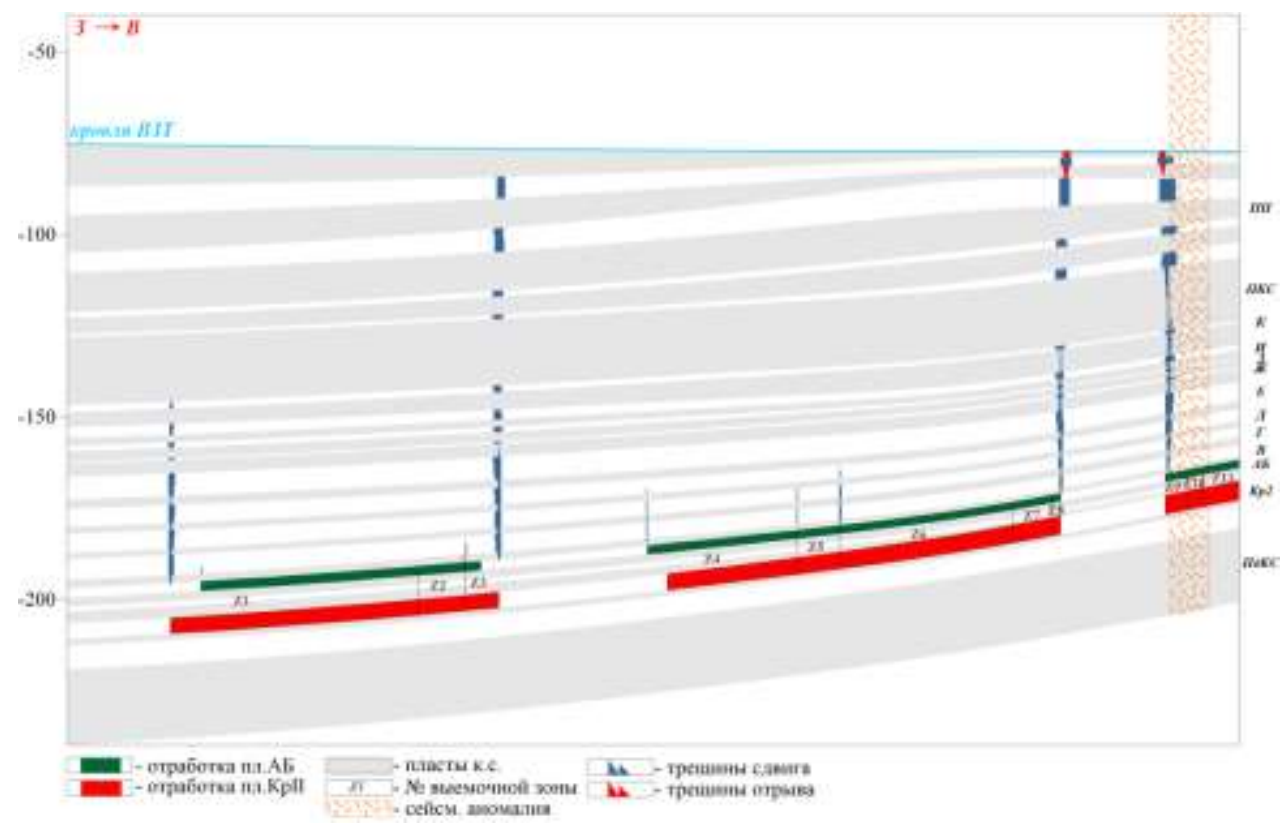

Рис. 3. Характер техногенного нарушения сплошности ВЗТ на конец процесса сдвижения без создания зоны смягчения

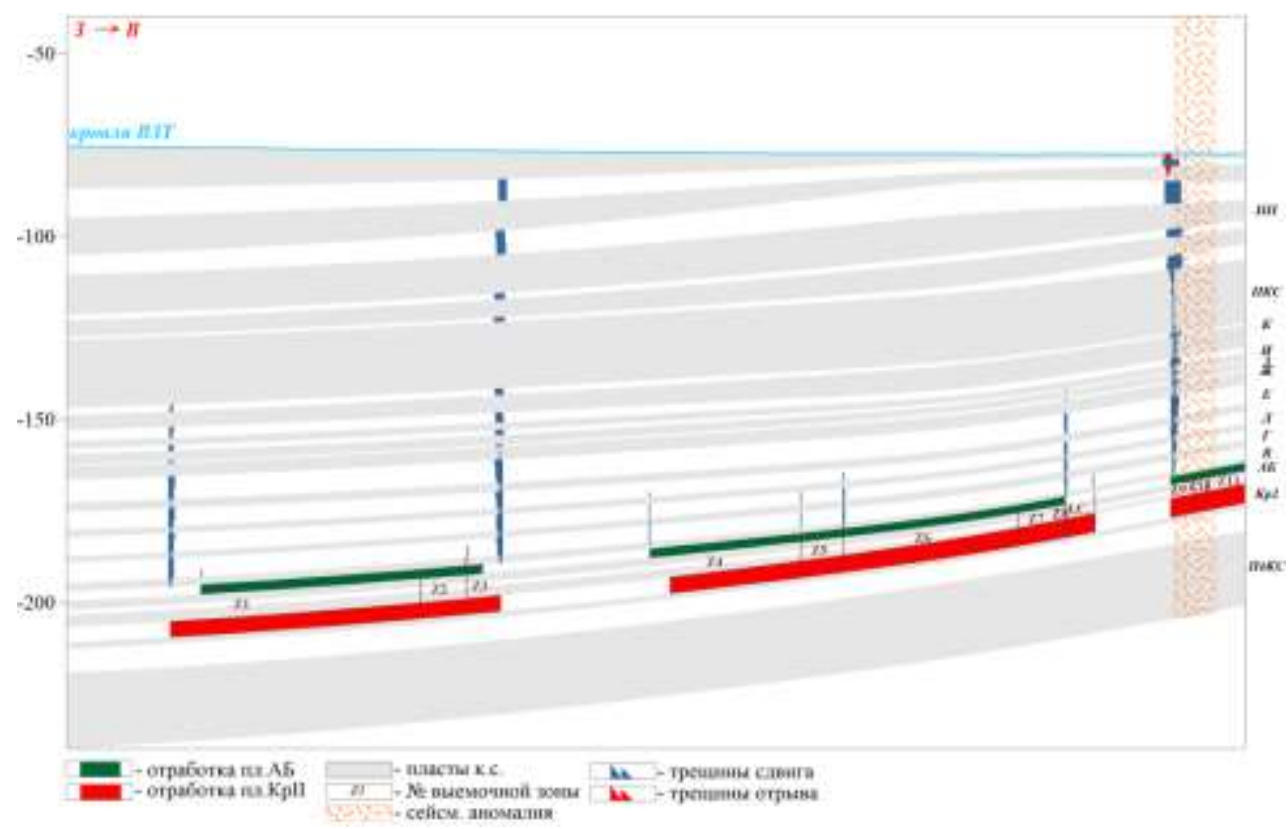

Рис. 4. Характер техногенного нарушения сплошности ВЗТ на конец процесса сдвижения с учетом создания зоны смягчения

\section{БИБЛИОГРАФИЧЕСКИЙ СПИСОК}

1. Указания по защите рудников от затопления и охране подрабатываемых объектов в условиях Верхнекамского месторождения калийных солей: утв. ПАО «Уралкалий», ЗАО «Верхнекамская калийная компания», ООО «ЕвроХим-Усольский Калийный комбинат». - введ. в действие 30.03.2017 в ред. 2014 г. Пермь; Березники, 2014. - 130 с.

2. Baryakh A.A., Samodelkina N.A Rheological analysis of geomechanical processes // Journal of Mining Science. - 2005. - V. 41, № 6. - P. 522-530. DOI: 10.1007/s10913-006-0015-x.

3. Кузнецов Г.Н. Механические свойства горных пород. - М.: Углетехиздат. - 1947. - 180 с.

4. Зенкевич О. Метод конечных элементов в технике / О. Зенкевич. - М.: Мир, 1975. - 541 с.: ил.

5. Малинин Н.Н. Прикладная теория пластичности и ползучести. - М.: Машиностроение, 1975. - 400 с

6. Фадеев А.Б. Метод конечных элементов в геомеханике. - М.: Недра, 1987. - 221 с.: ил. 